\title{
Evaluation of the Effectiveness of Computer Assisted Learning to Improve the Clinical Examination Skills of First Year Medical Undergraduates
}

\section{Gauhar Hussain *1, Ibrahim Farooque ${ }^{2}$.}

${ }^{* 1}$ Assistant Professor, Department of Physiology, F.H. Medical College, NH-2, Tundla, Firozabad (U.P.), India.

${ }^{2}$ Associate Professor, Department of Physiology, F.H. Medical College, NH-2, Tundla, Firozabad (U.P.), India.

\section{ABSTRACT}

Background: In present scenario, in most of medical colleges, basic clinical examination is being taught in physiology labs where patients are not available. Due to this, students find difficulty in learning, developing interest and understanding applied part. To overcome this we may develop some perceptions about clinical things with help of computers.

Material and methods: In this study, $751^{\text {st }}$ year MBBS students participated for learning through computer assistance in addition to traditional teaching of clinical examination of precordium at separate occasions. They were evaluated for the knowledge through test pre and post CAL examination. They have given their feedback about CAL also.

Results: After CAL, more students passed the same test.90.7\% students found CAL as more informative and $93.3 \%$ students said that they perceived better by CAL.

Conclusion: It was found that CAL has advantage over traditional learning and students achieved the learning objective better, which should be supplemented even in labs in clinical teaching.

KEY WORDS: Computer Assisted Learning (CAL), Precordium examination, M edical Physiology.

Address for correspondence: Dr. Gauhar Hussain, Assistant Professor, Department of Physiology, F.H. Medical College, NH-2, Tundla, Firozabad (U.P.), India. M obile No.: +919837512840

E-Mail: g_h303@yahoo.co.in

\begin{tabular}{|c|c|c|}
\hline \multicolumn{3}{|c|}{ Online Access and Article Informtaion } \\
\hline \multirow{2}{*}{ 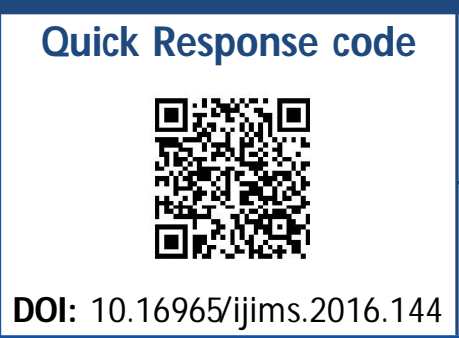 } & \multicolumn{2}{|c|}{$\begin{array}{l}\text { International Journal of Integrative Medical Sciences } \\
\text { www.imedsciences.com }\end{array}$} \\
\hline & $\begin{array}{l}\text { Received: 08-08-2016 } \\
\text { Reviewed: 09-08-2016 }\end{array}$ & $\begin{array}{l}\text { Accepted: 22-08-2016 } \\
\text { Published: 31-08-2016 }\end{array}$ \\
\hline Source of Funding: Self & & interest: None \\
\hline
\end{tabular}

\section{BACKGROUND}

Physiology is the study of functions of living organism as a whole or its constituent parts. Physiology is the basis of medicine which includes study of all mechanisms of normal body functioning. This is the basic science which is usually taught in first year of medical education curriculum. Graduate medical curriculum is oriented towards training students to undertake the responsibilities of a physician of first contact who is capable of looking after the preventive, curative and rehabilitative aspect of medicine [1].

It is important that the students should appreciate the importance of physiology and learn to apply that knowledge appropriately in a given clinical context. Physiology courses continue to rely on laboratory observation to provide students with practical information to correlate with their developing base of conceptual knowledge. The laboratories provide a functioning example of interactions among organ systems 
and a source of data for analysis. Practicals including hematology experiments and clinical examination are an integral and essential part of physiology teaching. We feel a teaching method can be successful and will be able to draw students' attention when it is not only interesting, informative and clinically oriented but also able to fetch better marks for the students in the examinations and assessment tests.

The teacher will help students to adopt an alternative approach to a laboratory class and is important to provide as much support to them as possible. The first step is to make them aware of the existence of alternative approaches which can be achieved through the normal academic dissemination vehicles (conference presentations, journal articles) or via Internet databases several of which already exist. To be effective a computer-based alternatives must be integrated into teaching and become part of the assessment process [2].

Nowadays, under medical education technology, various teaching learning methods are available to teach medical students. It is possible to use computers in medical education in lectures that is usually didactic. The focus in teaching is now shifting from didactic to active and Socratic one. The multimedia is being used positively and lectures have been improved. It is becoming "a truth universally acknowledged" that the education of undergraduate medical students will be enhanced through the use of computer assisted learning [3]. Simpson B. defined computer assisted learning (CAL) as "learning that supplements regular classroom activities with computer activities during or surrounding classroom time" [4].

But the use of this multimedia is confined only to the lectures and didn't have a proper place in labs and practical class rooms. Medical education and learning has been heavily concentrated on skills and competency assessment, and suggests that attention should rather be devoted to the development of clinical reasoning skills $[5,6]$. Laboratory teaching in most of the medical colleges is still restricted to the traditional methods of teaching. Faculties, demonstrators or residents, tell the procedure with help of blackboard and then demonstrate the procedure and possible findings in human subject. The students simply mimic and practice the same methodology. Computer assisted medical education offers a feasible and practical method of learning [3]. The incorporation of computer assisted instruction (CAI) in the student's curricula reduces the instructor's teaching time, increasing the time available to monitor individual students' performance, improving the student's attitude toward the course [7].

The study of CAL application and the acquisition of psychomotor skills among students and the relationship to teaching methodologies is a relatively new area of research in medical education $[8,9]$. Use of computer-assisted instructional material as an adjunct to teaching health sciences schools is increasing $[10,11]$.

However, work in the area of CAL remained largely under-searched. This study is designed to investigate the outcome of computer assisted learning in clinical physiology practicals. The intent of the study is to supplement classroom teaching by creating a virtual clinical experience using computer.

\section{MATERIALS AND METHODS}

$1^{\text {st }}$ year M BBS students were taken as subjects. Total 75 students, aged between 19 to 21 years, were included in the study. These students attended the physiology practical class on the day allotted for practical as per their time table.

The study protocol was approved by the Institutional Ethical Committee. Written informed consent was taken from each subject before entering in study and purpose of the study was explained to the students.

Total 75 students participated in the study. The topic for CAL was the practical examination of precordium as a part of clinical examination of cardiovascular system.

The study was conducted in 3 steps on separate occasions. At the end of each session, the volunteers had approximately 20 minutes to complete a questionnaire, which had been previously explained, to ensure that each question was clearly understood by the participants.

In the first and second session, the question- 
naires for knowledge test were composed of $M C Q s$ related to the practical procedure and possible findings/signs in that systemic examination.

In the last session, the questionnaire was having semi-structured and unstructured questions covering a number of issues including knowledge, attitudes towards CAL and its usability.

Survey respondents had to choose between Agree/Disagree

\section{Step I: $1^{\text {st }}$ and $2^{\text {nd }}$ week: Traditional way of teaching}

(a) Explaining the examination of precordium with the help of blackboard

(b) Demonstration of procedure/steps on human live subject

(c) Performance/practice by students in lab on subjects (on each other)

(d) Test of knowledge about practical (Pre CAL test): containing $16 \mathrm{M}$ CQs based on precordium examination practical.

\section{Step II: $3^{\text {rd }}$ week: Computer assisted learning}

(a) Use of multimedia educational material (videos and photographs of clinical examination) by LCD projector (guided by faculty, explaining important steps of procedure where required)

(b) Performance/practice by students in lab on human subjects

(c) Test of knowledge about practical (Post CAL test): containing the same set of $16 \mathrm{MCQs}$ (flipping the number of questions and options randomly to prevent preoccupied answers in their mind)

\section{Step III: $4^{\text {th }}$ week: Revision and Feedback questionnaire}

Feedback about perception, knowledge, advantage and limitations of CAL. This feedback was obtained by one questionnaire containing 15 questions.

Data analysis was done using SPSS (version 17.0). The McNemar test was used to assess the effectiveness of CAL in bringing about improvement in knowledge of students. The difference in the marks between 2 groups (pre and post $(\mathrm{CA}$ ) was analyzed by paired t-test and $p$-value $\varangle 0.05$ was considered significant.
Response to the various questions about CAL was shown as percentage.

\section{RESULTS}

Total 75 students participated in the study. They were tested before and after the computer assisted learning in clinical examination of precordium. The test consisted of 16 MCQs related to the knowledge of practical topic. The passing mark for test was $50 \%$. The results were analyzed for total passed students in both the sittings (pre CAL and post CAL) and compared. Second part of result is the analysis of perception and knowledge about the advantage and limitations of CAL by feedback.

Table 1: Comparison of students passed in test.

\begin{tabular}{|c|c|c|}
\hline $\begin{array}{c}\text { Assessment } \\
\text { time }\end{array}$ & $\begin{array}{c}\text { No. of students } \\
\text { passed }\end{array}$ & $\begin{array}{c}\% \text { of students } \\
\text { passed }\end{array}$ \\
\hline Pre CAL & 42 & 56 \\
\hline Post CAL & 62 & 82.67 \\
\hline
\end{tabular}

Table 1 shows the number of students who passed the test in the two sittings (pre and post $\mathrm{CAL}$ ). M cNemar's test determined that there was a statistically significant difference in the proportion of students who passed in the test (pre and post CAL), $p \varangle 0.001$.

Fig. 1: $M$ arks in the study group before and after CAL.

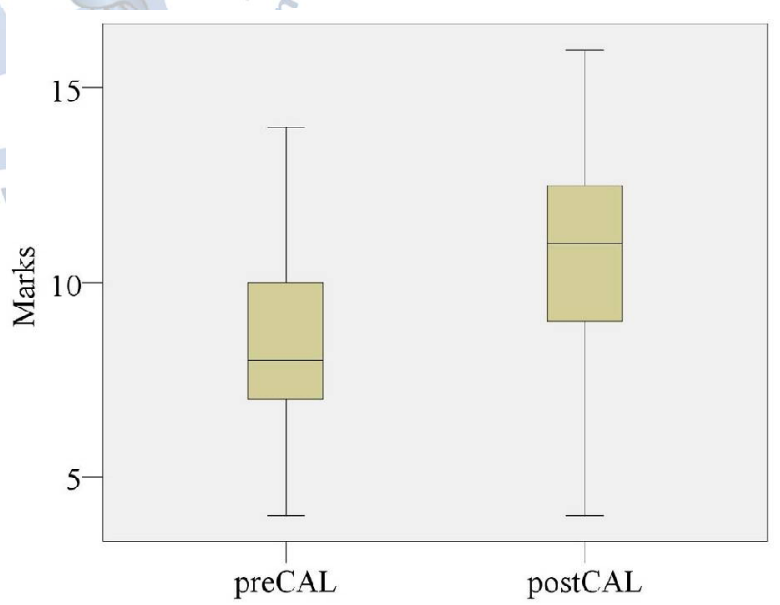

Figure 1 shows the marks of the students in the test at both occasions. The average was $8.32( \pm 2.42)$ before CAL which increased to 10.61( \pm 2.62$)$ after it. Paired sample t-test was used to analyze the difference between the marks on the two occasions and it was found to be highly significant $(p \measuredangle 0.001)$.

Table 2 shows the responses of the students about CAL. Majority of students have indicated that CAL has a number of perceived advantages 
to them. CAL helped them to understand the clinical aspects of physiology better. The results also indicate that $1^{\text {st }}$ year MBBS students appreciate and support CAL in physiology clinical practicals. CAL meets the majority of learning objectives. But students mentioned that CAL cannot provide actual feel of clinical examination and cannot replace traditional method of teaching.

Table 2: Response in feedback questionnaire for each question.

\begin{tabular}{|c|c|c|c|}
\hline S. No. & Question & Agree $(\%)$ & Disagree $(\%)$ \\
\hline 1 & I enjoyed CALteaching & 100 & 0 \\
\hline 2 & It aroused the interest in topic & 97.3 & 2.7 \\
\hline 3 & CAL was more informative & 90.7 & 9.3 \\
\hline 4 & I perceived the topic better by CAL & 93.3 & 6.7 \\
\hline 5 & Helped to retain concepts longer & 97.3 & 2.7 \\
\hline 6 & Hel ped to achieve learning objective & 96 & $\ln 45$ \\
\hline 7 & CAL is necessary al ong with human subject & 90.7 & 9.3 \\
\hline 8 & $\begin{array}{l}\text { Students can study outside the class by using } \\
\text { similar materials }\end{array}$ & 56 & 44 \\
\hline 9 & Absent students can also learn & 49.3 & 50.7 \\
\hline 10 & $\begin{array}{l}\text { linical signs clearly visualized with help of } \\
\text { CAL }\end{array}$ & 88 & 12 \\
\hline 11 & Topic becomes easy with CAL & 93.3 & 6.7 \\
\hline 12 & $\begin{array}{l}\text { We can avoid human subject with CALLit is a } \\
\text { complete substitute) }\end{array}$ & 34.7 & 65.3 \\
\hline 13 & $\begin{array}{l}\text { CAL provides real touch feeling of clinical } \\
\text { examination }\end{array}$ & 45.3 & 54.7 \\
\hline 14 & $\begin{array}{l}\text { CAL provided } 3 \mathrm{D} \text { relationship and image as } \\
\text { in human subject }\end{array}$ & 72 & 36 \\
\hline 15 & $\begin{array}{l}\text { Trained teacher is not required to prepare } \\
\text { and run the class }\end{array}$ & 10.7 & 89.3 \\
\hline
\end{tabular}

\section{DISCUSSION}

The common goal of both the sessions was to reinforce concepts presented to the students in traditional teaching. The laboratory demonstrations were intended to complement, rather than replace, the traditional lecture format used to teach the course. All these led to arouse interest in the subject which was manifested in their academic performance. The academic improvement was measured by their score in the evaluation tests conducted after the learning session. The knowledge of learners was significantly increased after the CAL session when compared with traditional teaching session. This is in consistent with earlier studies which have shown that groups of students who studied with CAL had better results than groups using traditional way of learning [12-16].

In this study, students have indicated that CAL has a number of perceived advantages to them. CAL helped them to understand the clinical aspects of physiology better. The results of the questionnaire elucidate that $1^{\text {st }}$ year $\mathrm{MBBS}$ students appreciate and support CAL in physiology clinical practicals. Most important advantage of CAL is that they meet the majority of learning objectives. This is consistent with study by Dewhurst et al in intestinal absorption physiology study in America [17]. Some studies even demonstrated that students studied with CAL need shorter time to reach the learning objectives, achieving better results than students who did not have access to CAL $[18,19]$. A study done by Govindaraja found that CAL makes undergraduate students understanding better in both theoretical as well practical aspects and helps them fulfill the learning outcomes [20]. In 1987, Clarke [21] demonstrate in his studies that the computer-based alternatives are able to achieve many of the learning objectives of practical classes which traditionally use animals with the exception of teaching and practicing both generic and specific laboratory.

Results from this study demonstrate that that $1^{\text {st }}$ year M BBS students appreciate and support CAL in physiology clinical practical's. Students have indicated that they can observe simultaneously with clear visualization of images and pictures of clinical signs by using computer and LCD projector. Students also felt that CAL facilitated them to understand and study clinical signs better as they are not posted in clinical wards. In such case CAL is very helpful to $1^{\text {st }}$ year M BBS students to learn the applied physiology. Students can repeatedly study the clinical signs even after the class. Students felt that they can maintain visual impression of clinical features for longer time. This will enhance their learning process and will definitely improve their performance during exam. Brain et al [22] assessed the effect of a computer based teaching program on pharmacology and pathophysiology of inflammation among 78 second year medical students. While the program was found to be effective in terms of increase in knowledge it 
was also opined by students that such program should complement rather than replace traditional lectures.

Despite all benefits of CAL, there are few disadvantages and limitations.CAL limits the direct interaction with the living tissue. There are certain skills that cannot be adequately taught without live subject. Typically the teacher decides on which experiments to include, which experimental parameters to be dealt, how much background information to provide, which selfassessments to include etc. The contents could turn out to be too lengthy and overloaded with information if they are not properly designed $[23,24]$. Undoubtedly the approach of students will not be the same as that of teachers. There should be consistent feedback from students $[25,26]$.

In this study many students mentioned that CAL cannot provide actual feel of clinical examination of human subject. Potential loss of contact with tutors could be a limiting factor [24].

\section{CONCLUSION}

The performance of students was improved when they received CAL along with traditional method. Through CAL, student's interest, concentration and understanding of topic was definitely increased. The computer based assisted learning have the potential to raise teaching standards to new level of sophistication, but it should be taken as supplement to traditional teaching, not a complete replacement.

Hence we suggest that in teaching clinical physiology, CAL should be implemented in medical curriculum. All medical teachers should undergo training of basic computer sciences and medical education technology, which will definitely improve teaching and learning process among medical students as well as medical teachers.

\section{ACKNOWLEDGEM ENT}

The authors thank all the students who participated in the study.

\section{REFERENCES}

[1]. Salient features of Regulations on Graduate M edical Education, 1997 (Internet). 1997. Published in part iii, section 4 of the Gazette of India dated 17th M ay
1997. [http://www.mciindia.org/Rules and Regulations/Graduate Medical Education Regulations1997.aspx]

[2]. Dewhurst, D. G. and Hughes E. The pharma-CAL-ogy project- is there life after death? Brit. J. Pharmac. Proc. suppl. 1999;127:89.

[3]. Greenhalgh T. Computer assisted learning in undergraduate medical education. BMJ. 2001;322:40-4.

[4]. Simpson B. Web-based and computer-assisted instruction in physical therapy education. J Phys Ther Educ. 2003;17(2):45-9.

[5]. Chamberlain N, Yates H. Use of a computer assisted clinical case (CACC) SOAP note exercise to assess students' application of osteopathic principles and practice. J Am Osteopath Assoc. 2000;100:437-40.

[6]. Scott-Smith W. The development of reasoning skills and expertise in primary care. Educ Prim Care. 2006;17:117-29.

[7]. Puri R, Bell C, Evers WD. Dietetics Students' Ability to Choose Appropriate Communication and Counseling Methods Is Improved by Teaching Behavior-Change Strategies in Computer-Assisted Instruction. J Am Diet Assoc. 2010;110:892-7.

[8]. Besson S, Kring D. The effects of two teaching methods on nursing students' factual knowledge and performance of psychomotor skills. J Nurs Educ. 1999;38:357-9.

[9]. Smith A, Jones J, Cavanaugh C, Venn J, Wilson W. Effect of interactive multimedia on basic clinical psychomotor skill performance by physical therapy students. J Phys Ther Educ. 2006;20(2):61-7.

[10]. Berube D, Murray C, Schultze K. Cadaver and computer use in the teaching of gross anatomy in physical therapy education. J Phys Ther Educ. 1999:13:41-46.

[11]. McNulty JA, Halama J, Dauzvardis M, Espiritu B. 2000. Evaluation of Web-based computer-aided instruction in a basic science course. Acad Med. 2000;75:59-65.

[12].Plasschaert AJ, Wilson NH, Cailleteau JG, Verdonschot EH. Opinions and experiences of dental students and faculty concerning computerassisted learning. J Dent Educ1995;5:1034-1040.

[13]. Preston JD. Computers in dental education. J Calif Dent Assoc 1997;25:729-733.

[14]. Plasschaert AJ, Cailleteau JG, Verdonschot EH. The effect of a multimedia interactive tutorial on learning endodontic problem solving. Eur J Dent Educ 1997;1:66-69.

[15]. Hawley GM, Hamilton FA, M urray F, Baggett FJ. Evaluation of a teaching aid for dental students. Eur JDent Educ 1998:2:133-137.

[16]. Ayoub JL, Vanderboom C, Knight M, Walsh K, Briggs R, Grekin K. A study of the effectiveness of an Interactive Computer Classroom. Computers in Nursing 1998;6: 333-338.

[17]. Dewhurst, D. G., Brown, G. J. and Mehan, A. S. Microcomputer simulations of laboratory experiments in physiology. ATLA 1988;15:280-289. 
[18]. Lenherr P, M arinello CP. PrepCheck computergestützte objektive Beurteilung von Zahnpräparationen im Simu-lationslabor. Swiss Dent J 2014;124(10):1085-92.

[19]. Cardoso JA, Barbosa C, Fernandes S, et al. Reducing sub-jectivity in the evaluation of preclinical dental preparations for fixed prosthodontics using the Kavo PrepAssistant. Eur J Dent Educ 2006;10:14956.

[20]. Govindaraja C, Jaiprakash H, Annamalai C, Vedhavathy SS. Computer assisted learning: Perceptions and knowledge skills of undergraduate medical students in a Malaysian medical school. Natl J Physiol Pharm Pharmacol. 2011;1(2):63-67.

[21]. Clarke, K. The use of microcomputer simulations in undergraduate neurophysiology experiments. ATLA 1987;14:134-140.

[22]. Brain S, Dewhurst D, Williams A. Evaluation of the usefulness of a computer based learning program to support student learning in pharmacology. ALT-J. 1999;7:37-45.
[23]. Dewhurst D G, Norris TAM. Helping teachers to embed e-learning materials into undergraduate pharmacology courses. Bioscience Education. 2003;1(1). DOI: 10.3108/beej.2003.01010006

[24].Lenherr P, Marinello CP. PrepCheck computergestützte objektive Beurteilung von Zahnpräparationen im Simulationslabor. Swiss Dent J 2014;124(10):1085-92.

[25]. Cardoso JA, Barbosa C, Fernandes S, et al. Reducing sub-jectivity in the evaluation of preclinical dental preparations for fixed prosthodontics using the Kavo PrepAssistant. Eur J Dent Educ 2006;10:14956.

[26]. Kournetas N, Jaeger B, Axmann D, et al. Assessing the reliability of a digital preparation assistant system used in dental education. J Dent Educ 2004;68(12):1228-34.

How to cite this article:

Gauhar Hussain, Ibrahim Farooque. Evaluation of the Effectiveness of Computer Assisted Learning to Improve the Clinical Examination Skills of First Year Medical Undergraduates. Int J Intg Med Sci 2016;3(8):391-396. Dol: 10.16965/ijims.2016.144 